\title{
Nursing Care on Improving Postoperative Condition in CIPA Patients Combined with Charcot Spine
}

\author{
Bingdu Tong \\ Peking Union Medical College Hospital \\ Zhengye Zhao \\ Peking Union Medical College Hospital \\ Ye Tian \\ Peking Union Medical College Hospital
}

\section{Siyi Cai}

Peking Union Medical College Hospital

\section{Jianguo Zhang}

Peking Union Medical College Hospital

\section{Nan Wu ( $\nabla$ dr.wunan@pumch.cn )}

Peking Union Medical College Hospital https://orcid.org/0000-0002-9429-2889

\section{Yaping Chen \\ Peking Union Medical College Hospital \\ $\mathrm{Na}$ Guo \\ Peking Union Medical College Hospital}

\section{Research}

Keywords: Congenital insensitivity to pain with anhidrosis (CIPA), Charcot spine, Nursing care, Temperature monitoring, Posture management

Posted Date: January 5th, 2021

DOI: https://doi.org/10.21203/rs.3.rs-139013/v1

License: (c) (i) This work is licensed under a Creative Commons Attribution 4.0 International License. Read Full License 


\section{Abstract}

Background

Congenital insensitivity to pain with anhidrosis (CIPA) is a rare, hereditary, sensory autonomic neuropathy. There are few reports on CIPA combined with Charcot spine. Operation is a most effective method for CIPA patients who combine with Charcot spine, but those patients are easy to get hyperthermia and internal fixation failure after operation. Patients' deficit teeth also make nutrition management difficult. In order to help patients to avoid these problems, we designed a series of preoperative and postoperative nursing means: 1. Rectal temperature monitoring and Temperature control 2. Use new posture management 3 . Assess the nutritional status of patients and make a diet plan. In this study, we aimed to evaluate the effect of these nursing means.

\section{Methods}

We retrospectively analysed the records of 3 CIPA patients combined with Charcot spine who accepted our nursing means to examine the effect of the nursing means.

Results

Rectal thermometry was more accurate than axillary thermometry. Physical cooling prevented hyperthermia for CIPA patients after operation. None of 3 patients had internal fixation failure. The BMI of one patient was only 14.0 (malnutrition) before surgery, through nutritional intervention, all 3 patients' serum albumin levels returned to normal before discharge from the hospital.

\section{Conclusions}

In summary, this study has made a lot of suggestions that can improve the prognosis of CIPA patients with Charcot spine.

\section{Background}

Congenital insensitivity to pain with anhidrosis (CIPA) is a rare, hereditary, sensory autonomic neuropathy, characterized by absence of reaction to painful stimuli[1], inability to sweat and mental retardation[2, 3], it also can induce the destruction of the joint - neuropathic arthropathy (Charcot joint, Charcot spine). There are few reports associated with CIPA combined with the Charcot spine[4], and there is no standard treatment[5,6]. CIPA is a really dangerous disease, and most patients cannot live over 25 years[7]. Operation is a most effective and reasonable method for those patients combined; however, there are also many challenges for patients to have the operation. For example, besides sensory autonomic neuropathy, patients are also insensitive to pharmaceutical cooling[8], they are easy to get hyperthermia or convulsion, or they can die of secondary infection caused by hyperthermia. The absence of reaction to painful stimuli is easy to cause internal fixation failure due to hypermobility. CIPA patients bleed more in $360^{\circ}$ fusion operation, and they also have deficit teeth, which makes nutrition management difficult. We designed a series of nursing means to improve the prognosis of CIPA patients. The goals of this study are as follows: 1 . to evaluate the effect of body position management. 2. to evaluate the effect of body temperature monitoring and control. 3. to assess the nutritional status of patients and make a diet plan.

\section{Methods}

Three CIPA patients with Charcot spine who received surgeries in our hospital from January 2010 to September 2019 were studied. In these 3 patients, besides lumbar vertebral injuries, CIPA can also do damage to the ankle, elbow, knee, and hip joint. The general information of the patients is shown in Table 1. The Mean operation age of these patients was $19.67 \pm$ 
5.03 (15-25). The average length of stay (ALOS) was $24.67 \pm 6.03$ days (19-31 days). The Median follow-up time was 14 months (6-124 months).

Table 1

General information of the patients with CIPA

\begin{tabular}{|c|c|c|c|c|c|c|c|c|c|}
\hline Case & Age & $\begin{array}{l}\text { Affected } \\
\text { area }\end{array}$ & Operative name & $\begin{array}{l}\text { Operation } \\
\text { time } \\
\text { (min) }\end{array}$ & $\begin{array}{l}\text { Blood } \\
\text { loss } \\
(\mathrm{ml})\end{array}$ & $\begin{array}{l}\text { Blood } \\
\text { transfusion } \\
(\mathrm{ml})\end{array}$ & $\begin{array}{l}\text { Length } \\
\text { of stay } \\
\text { (d) }\end{array}$ & $\begin{array}{l}\text { Follow- } \\
\text { up } \\
\text { (month) }\end{array}$ & $\begin{array}{l}\text { Total } \\
\text { drainage } \\
\text { volume } \\
(\mathrm{ml})\end{array}$ \\
\hline 1 & 15 & $\begin{array}{l}\text { Lumbar, } \\
\text { ankles }\end{array}$ & $\begin{array}{l}\text { Posterior } \\
\text { osteotomy (L2-3), } \\
\text { kyphosis } \\
\text { correction, excision } \\
\text { of intraspinal } \\
\text { mass, internal } \\
\text { fixation, Pyramesh } \\
\text { vertebral } \\
\text { reconstruction, } \\
\text { autogenous bone } \\
\text { graft fusion }\end{array}$ & 345 & 1200 & $\begin{array}{l}\text { RBC 8u } \\
\text { FFP } 800\end{array}$ & 31 & 124 & $\begin{array}{l}700 \\
\text { POD2 }\end{array}$ \\
\hline 2 & 25 & $\begin{array}{l}\text { Lumbar, } \\
\text { left } \\
\text { elbow, } \\
\text { left hip, } \\
\text { left } \\
\text { knee, } \\
\text { left } \\
\text { ankle }\end{array}$ & $\begin{array}{l}\text { Right posterior } \\
\text { iliac bone } \\
\text { extraction, } \\
\text { posterior vertebral } \\
\text { body partial } \\
\text { resection (L3, L4), } \\
\text { interbody fusion } \\
\text { (L2 / 3, L4 / 5, L5 / } \\
\text { S1), spinal canal } \\
\text { decompression(L2- } \\
\text { S1), internal } \\
\text { fixation, bone graft } \\
\text { fusion }\end{array}$ & 480 & 1200 & $\begin{array}{l}\text { RBC } 4 \mathrm{u} \\
\text { FFP } 400\end{array}$ & 24 & 14 & $\begin{array}{l}850 \\
\text { POD5 }\end{array}$ \\
\hline 3 & 19 & $\begin{array}{l}\text { Lumbar } \\
\text { spine, } \\
\text { left } \\
\text { elbow, } \\
\text { left } \\
\text { knee, } \\
\text { right } \\
\text { ankle }\end{array}$ & $\begin{array}{l}\text { Posterior left iliac } \\
\text { bone extraction, } \\
\text { part of L1 and L3 } \\
\text { vertebral bodies } \\
\text { and L2 vertebral } \\
\text { body osteotomy, } \\
\text { osteotomy space } \\
\text { bone graft, pedicle } \\
\text { screw fixation(T10- } \\
\text { S1), interbody } \\
\text { fusion (L4-5, L5- } \\
\text { S1), bone graft } \\
\text { fusion (L4-5, L5- } \\
\text { S1, T10-S1) }\end{array}$ & 385 & 1500 & $\begin{array}{l}\text { ABT } 750 \\
\text { RBC 5u } \\
\text { FFP } 600\end{array}$ & 19 & 6 & $\begin{array}{l}1365 \\
\text { POD7 }\end{array}$ \\
\hline
\end{tabular}

The nursing measures is described in Table 2. 


\section{Routine care}

Preoperative examination and evaluation

Physical examination on admission

Post admission examination

\section{Specific nursing}

\section{Body position}

Bed rest: do preoperative evaluation of spinal cord compression, have bed rest if necessary

Body position change: teach patients the method of bed and chair transfer, lying down $\rightarrow$ sitting up and sitting up $\rightarrow$ lying down

Standing: wear braces until internal fixation fusion is completely stable; use tripeptide to accelerate bone healing

\section{Temperature monitoring and prevention of hyperthermia}

Preoperative: monitoring axillary temperature and evaluating patients' tolerance to postoperative actual temperature monitoring

Intraoperative: actual and nasal temperature monitoring

\section{Nerve function monitoring}

Intraoperative spinal cord monitoring

Dynamic monitoring of sensation, movement, urine and stool

Postoperative: actual temperature and axillary

temperature (Figure) monitoring

\section{Psychology}

Encourage patients to express

Carefully observe the abnormal physical signs and behaviors of patients, find out the causes, and do nursing intervention

\section{Gastrointestinal management (diet, excretion)}

Assess the nutritional status of patients and make a diet plan (Figure)

Promote the recovery of gastrointestinal function after operation

\section{Wound drainage}

Observe the volume of drainage to ensure that the drainage is sufficient. Avoid hyperthermia caused by heat absorption

\section{Function exercise}

During bedtime

Underground activities

\section{Blood volume management}

Monitor heart rate and blood pressure, keep blood volume stable

Follow the doctor's advice to use vasopressor drug if necessary

\section{The main points of nursing 1: Temperature monitoring and Prevention of hyperthermia.}

\section{Temperature monitoring:}

Rectal thermometry is recognized as the most accurate surrogate of body temperature, especially for hyperthermia patients[9]. We decided to monitor rectal temperature for these patients, compared the result of rectal temperature with axillary temperature. For rectal temperature monitoring, common ECG monitors (including ECG monitors of general company, Mindray Medical International, Philips, Siemens, and GE) can be used. It is necessary to prepare the temperature probe conversion line, which is suitable for the TEMP probe interface of the monitor in advance. A probe needs to be inserted into the rectum via the anus and kept in the patient's rectum. In order to ensure patients can tolerate and cooperate with rectal temperature monitoring after the operation: do a pre-operative rectal temperature monitoring for 
patients to assess their compliance and increase the likelihood of their postoperative cooperation. Measurement method: lubricate the probe and then put it into the intestinal cavity according to the clinical procedure. Caution: If resistance is felt while inserting the probe, stop the insertion and pull back the probe slightly. Do not force the probe in because improper placement may damage the patient's cavity mucosa. The probe has a scale, which can be used to determine the depth of probe placement and see whether the probe is falling off or retreating through the exposed scale.

Measure axillary temperature at $2 \mathrm{pm}$ every day before surgery. Measure the rectal temperature and axillary temperature at 6 pm-6 am-2 pm-6 pm every day since one day prior to the operation, to identify hyperthermia in time.

\section{Temperature control}

Prepare temperature and humidity instruments for patients, because they can't reduce the temperature by perspiration. Maintain the ambient temperature at $23 \pm 2{ }^{\circ} \mathrm{C}$. Reduce the patient's cover at the same time. The ice bag is used for physical cooling to avoid hyperthermia after the operation. If the rectal temperature is maintained between 37.5 to $38.5^{\circ} \mathrm{C}$, physical cooling is the main way to prevent hyperthermia or convulsion. If the rectal temperature is higher than $38.5{ }^{\circ} \mathrm{C}$ and the drop in body temperature is not substantial after physical cooling, it is necessary to use aspirin/lysine to lower the hypothalamus temperature set-point, despite the fact that CIPA patients are relatively insensitive to drug cooling.

\section{The main points of nursing 2: Posture management Bed rest}

Preoperative: evaluate the degree of spinal cord compression by imaging and determine whether patients should have bed rest before surgery. One patient in this study had spinal cord compression before surgery, so he was required to lie in bed before the operation. Due to the mental retardation and stubborn character of CIPA patients, he did not understand why he needed to lie in bed before the operation. He insisted on getting up and going to the bathroom. Family members could fully understand the importance of bed rest after the communication and they were required to accompany the patient 24/7. Family members worked with the medical staff to ensure that patient lies in bed before the operation. Avoid further compression of the spinal cord or paralysis caused by activities.

Postoperative: Because of the absence of reaction to painful stimuli, the patient's body position cannot be limited by pain. Teaching patients how to turn over and sit up can avoid the failure of internal fixation caused by excessive activity.

\section{Position change}

The postoperative bedtime is relatively long because of the osteoporosis and operation. An X-ray should be taken before the patients get out of bed to make sure that the internal fixation is stable.

\section{From lying position to standing position}

Before going down to the ground, patients should put on the brace in bed first, and then sit up beside the bed to avoid internal fixation loosening or even displacement as their body position changes (see Fig. 1). They should not directly sit up from the supine position. Because at this time the bending force is too large, which can easily cause the loosening of internal fixation.

\section{From standing position to lying position}

when the patients lie down from sitting up, they should be wearing the brace. The brace can be removed after lying down. (see Fig. 2). During the whole process of sitting up and lying down, the brace can disperse the stress, reduce the pressure of internal fixation, and minimize the risk of internal fixation loosening. 


\section{Underground activities}

Denervation of the bone can affect the healing. Teriparatide is used to promote the bone formation after the operation. Patients need to come back to the hospital for examination at the first, third, and sixth months after the operation. The results of the X-ray can be used to determine the time when the brace can be removed. Before the internal fixation is completely stable, the brace should be worn when changing the body position.

\section{The main points of nursing 3: Assess the nutritional status of patients and make a diet plan}

Nrs2002 is used to evaluate the status of patients. CIPA patients always have tooth problems[5, 10, 11]. Therefore, evaluation of patients' teeth and chewing ability should be done before making the intervention plan. (Fig. 3)

\section{Data Collection}

These patients were followed up by phone, and their outpatient or medical records were reviewed.

\section{Results}

\section{Temperature}

The changing trend of 3 patient's postoperative rectal and axillary temperature (Fig. 4).

\section{Nutritional status}

the BMI of one patient was only 14.0 (malnutrition) before surgery. Through nutritional intervention, all 3 patients' serum albumin levels returned to normal before discharge from the hospital(Figure 5).

\section{Discussion}

1. CIPA is a rare hereditary sensory autonomic neuropathy. It was first reported by Swanson in 1963[12]. There were few reports of CIPA in the previous literature. CIPA is more common in men, and all three patients in this study are female. Dyck named these diseases as Hereditary sensory and autonomic neuropathy (HSAN)[13]. HSAN has been categorized into 5 types: HSAN type I (Hereditary sensory radicular neuropathy), HSAN type II (Congenital sensory neuropathy), HSAN type III (Familial dysautonomia), HSAN Type IV (CIPA), and HSAN type V (Congenital insensitivity to pain with partial anhidrosis) $[2,14]$. The three cases reported in this study belong to type IV (CIPA).

2. The diagnosis of CIPA is based on pain, temperature test and iodine starch sweating qualitative test[15]. Further diagnosis requires molecular biotechnology to find out the location of gene mutation. In this study, all 3 cases are investigated by the above methods, and skin biopsies were performed in another hospital, which showed a loss of unmyelinated fibers of peripheral nerve, denervation of skin nerve and abnormality of exocrine gland. All the evidence supports the CIPA diagnosis.

3. Rectal thermometry is recognized as the most accurate surrogate of body temperature, especially for hyperthermia patients[9]. CIPA has a great impact on body temperature, so it is necessary to monitor the temperature of patients after operation. The axillary temperature is not accurate when the core body temperature is abnormal. We must pay attention to prevent death due to secondary infection caused by hyperthermia. 
CIPA, as a rare sensory autonomic neuropathy, affects sweating and heat dissipation. In this study, we first tried to use rectal and axillary temperature to reflect the trend of postoperative temperature change. Secondly, we tried to explain the cause of the temperature change. The time course of temperature showed two peaks, on the first day and 5-7 days after surgery, respectively. The changing trend of rectal and axillary temperature is similar, but the sensitivity of axillary temperature is not as good as that of the rectal temperature. Axillary temperature is easy to cause false-negative results, especially in the early postoperative period. It is suggested that rectal temperature should be used to reflect the temperature changes, especially in the early postoperative period.

The reasons for two peaks: the peak on the first day after surgery is considered to be related to surgery; the second peak on the 5-7 days after surgery is considered to be a fever following the removal of the drainage tube. CIPA patients' bone healing is slow and poor $[14,16,17]$, so they always get out of bed later than the regular patients. Before the removal of the drainage tube, the patients have to lay in the bed all the time. The surgical trauma is substantial, and there is much bleeding. After the removal of the drainage tube, there will be blood or fluid accumulation in the body, which leads to the second peak.

4. CIPA is similar to spinal cord injuries, especially the cervical spinal cord injury, because they all have sensory autonomic neuropathy, which can affect sweating and heat dissipation. Therefore, our study uses physical cooling to prevent hyperthermia caused by spinal cord injury, and it has achieved good results. Although CIPA patients are insensitive to drug cooling, we can still use aspirin/lysine to reduce their temperature by lowering the temperature set-point. It is confirmed that to some extent the method of CIPA postoperative temperature control can be applied the treatment of spinal cord injury.

5. CIPA combined with Charcot spine should have $360^{\circ} \mathrm{fusion}$, postoperative position management is very important. Vialle reported 9 cases of CIPA with Charcot spine and emphasized the importance of $360^{\circ}$ fusion. He pointed out that due to the lack of pain protection mechanism, the repeated excessive activity of patients is easy to cause the failure of internal fixation even in case of a simple posterior fusion [18]. Therefore $360^{\circ}$ fusion was performed in all 3 CIPA patients. $360^{\circ}$ fusion can provide the most powerful stability to prevent the internal fixation failure caused by excessive activity. $360^{\circ}$ fusion is important, but postoperative position management is also important. The position management is particularly important in the early postoperative period, especially in the period before the internal fusion is completely stable. Our method that ensure patients always wear braces during the whole process from lying position to standing position and from standing to lying position can disperse the stress of spine.

6. The BMI of one patient was only 14.0 (malnutrition) before surgery. Through our nutritional intervention, this patient returned to normal before discharge from the hospital. This result can confirm that our approach can really help patients.

\section{Declarations}

\section{Acknowledgements:}

We acknowledge all of the members of Department of Orthopedic Surgery, Peking Union Medical College Hospital for helpful support and the patients for participating in this study.

\section{Authors' contributions:}

All authors read and approved the final manuscript. NG and YCP designed this study, participated in the workshop, and supervised the manuscript. BDT and ZYZ coordinated the study, analyzed data, and wrote the final manuscript. YT and SYC collected and interpreted data. JGZ participated in study design and assisted in the collection of data. NW participated in the workshop and collaborated in the feasibility study and reviewed the manuscript. 


\section{Funding:}

No funding received.

\section{Availability of data and materials:}

The data analyzed during this study were obtained with the permission from the Peking Union Medical College Hospital from the corresponding author on reasonable request.

\section{Ethics approval and consent to participate:}

This study has been approved to the ethics committee at Peking Union Medical College Hospital.

\section{Consent for publication}

Consent for publication was obtained from all participants.

\section{Competing interests}

No competing interest.

\section{References}

1. Dearborn GvN. A case of congenital general pure analgesia. Journal of Nervous and Mental Disease, 1932.

2. Nagasako EM, Oaklander AL, Dworkin RH. Congenital insensitivity to pain: an update. Pain. 2003;101(3):213-9.

3. Dyck P. Neuronal atrophy and degeneration predominantly affecting peripheral sensory and autonomic neurons. Peripheral neuropathy, 1984: p. 1557-1599.

4. Sliwa JA, Rippe D, Do V. Charcot spine in a person with congenital insensitivity to pain with anhydrosis: a case report of re-diagnosis. Arch Phys Med Rehabil. 2008;89(3):568-71.

5. Rasmussen P. The congenital insensitivity-to-pain syndrome (analgesia congenita): report of a case. International journal of paediatric dentistry. 1996;6(2):117-22.

6. Piña-Garza JE, Fenichel's Clinical Pediatric Neurology: A Signs and Symptoms Approach (Expert Consult-Online and Print). 2013: Elsevier Health Sciences.

7. Daneshjou K, Jafarieh H, Raaeskarami S-R. Congenital insensitivity to pain and anhydrosis (CIPA) syndrome; a report of 4 cases. Iranian journal of pediatrics. 2012;22(3):412.

8. Bae C, et al. Dental Management in a Patient with Congenital Insensitivity to Pain with Anhidrosis: A Case Report. Journal of The Korean Academy of Pediatric Dentistry. 2019;46(4):416-21.

9. Niven DJ, Laupland KB, Stelfox HT. Accuracy of peripheral thermometers for estimating temperature. Ann Intern Med. 2016;165(1):73-4.

10. Narayanan V. Oral and maxillofacial manifestations of hereditary sensory neuropathy. Br J Oral Maxillofac Surg. 1996;34(5):446-9.

11. Bodner L, et al. Orofacial manifestations of congenital insensitivity to pain with anhidrosis: a report of 24 cases. Journal of dentistry for children. 2002;69(3):293-6. 
12. SWANSON AG. Congenital insensitivity to pain with anhydrosis: a unique syndrome in two male siblings. Arch Neurol. 1963;8(3):299-306.

13. DYCK PJ, et al. Not 'indifference to pain'but varieties of hereditary sensory and autonomic neuropathy. Brain. 1983;106(2):373-90.

14. Axelrod FB, Gold-von G, Simson. Hereditary sensory and autonomic neuropathies: types II, III, and IV. Orphanet J Rare Dis. 2007;2(1):39.

15. Mardy S, et al. Congenital insensitivity to pain with anhidrosis: novel mutations in the TRKA (NTRK1) gene encoding a high-affinity receptor for nerve growth factor. The American Journal of Human Genetics. 1999;64(6):1570-9.

16. Schulman $\mathrm{H}$, et al. Congenital insensitivity to pain with anhidrosis (CIPA): the spectrum of radiological findings. Pediatric radiology. 2001;31(10):701-5.

17. Beigelman A, et al. Abnormal neutrophil chemotactic activity in children with congenital insensitivity to pain with anhidrosis (CIPA): the role of nerve growth factor. Clinical Immunology. 2009;130(3):365-72.

18. Vialle R, et al. Charcot's Disease of The Spine: Diagnosis and Treatment. Spine. 2005;30(11):E315-22.

\section{Figures}

A

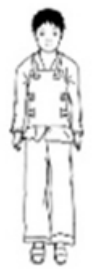

Standing

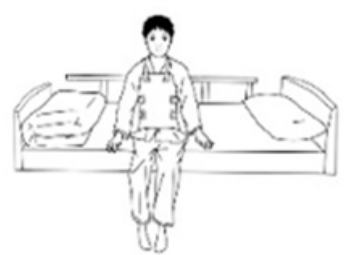

Sitting

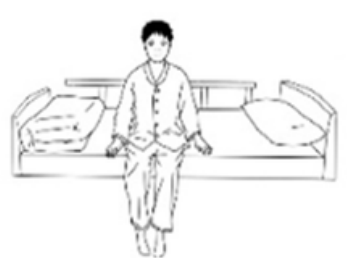

Removing Brace

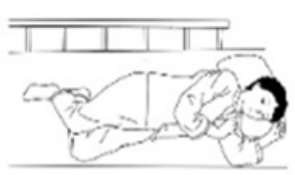

Lying

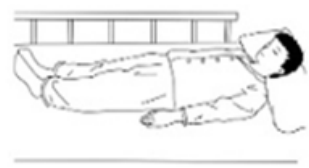

Supine

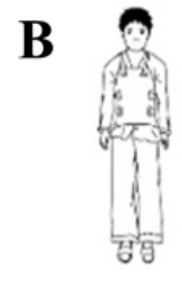

Standing

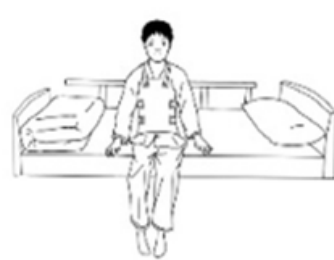

Sitting

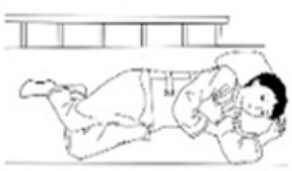

Lying

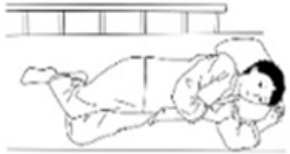

Removing Brace

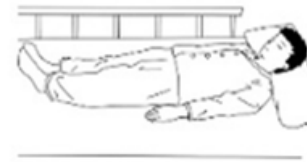

Supine

\section{Figure 1}

The comparation of postoperative nomal spinal disease patient and CIPA pateient from lying to standing ; A nomal spinal disease patient; B CIPA pateient 
A

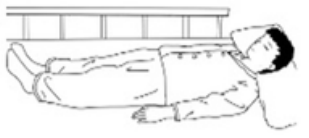

$$
\text { - }
$$

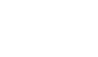

Lying

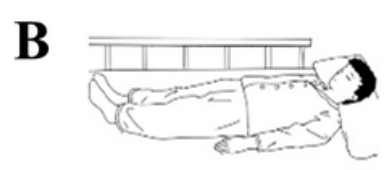

Lying

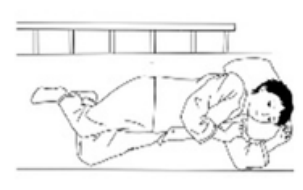

Lateral Position

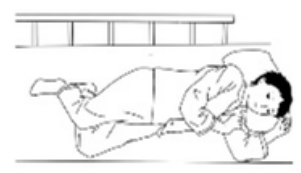

Lateral Position

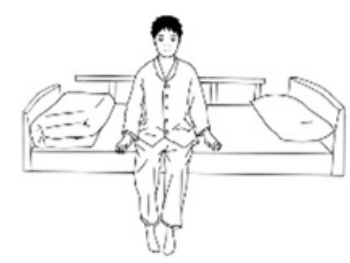

Sitting

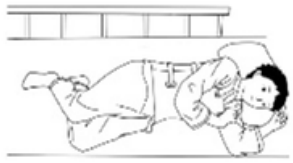

Wearing Brace

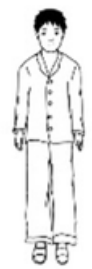

Standing

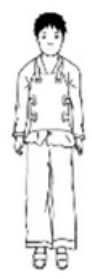

Wearing Brace

\section{Figure 2}

The comparation of postoperative nomal spinal disease patient CIPA patient from standing to lying ; A nomal spinal disease patient; B CIPA pateient 


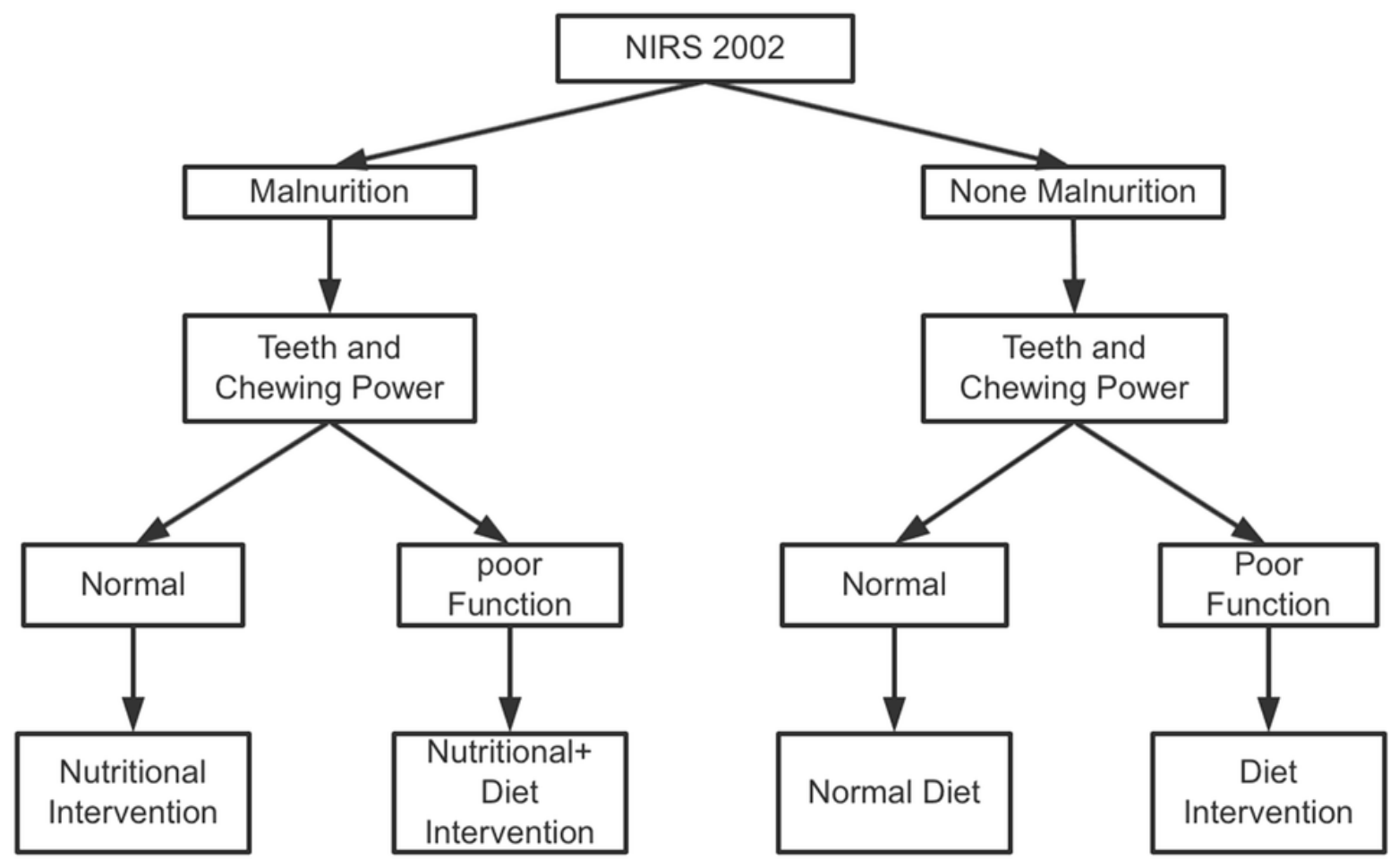

Figure 3

evaluation of patients' teeth and chewing ability 


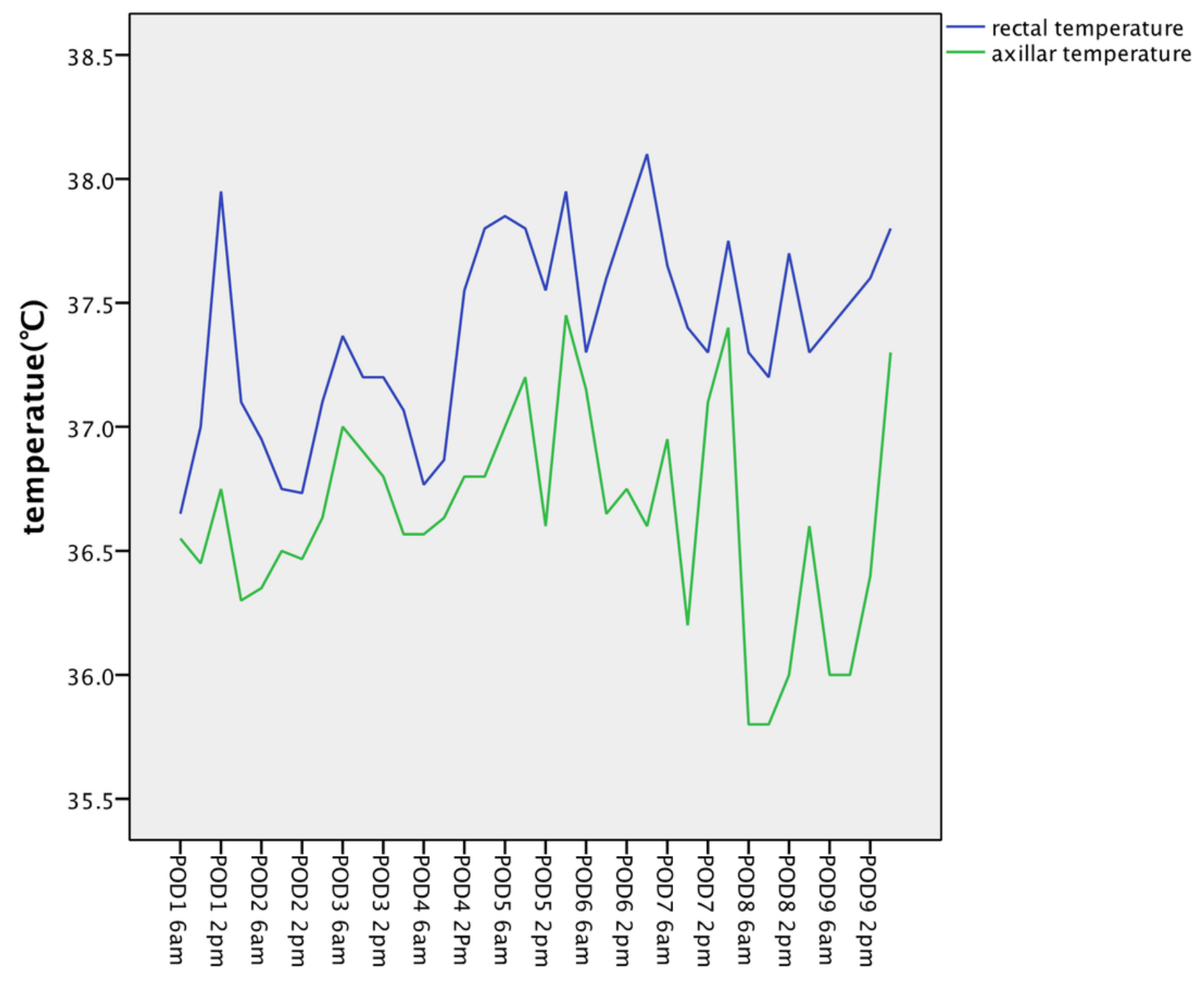

POD: Post-operative day

Figure 4

The change trend of 3 patient's postoperative rectal and axillary temperature 


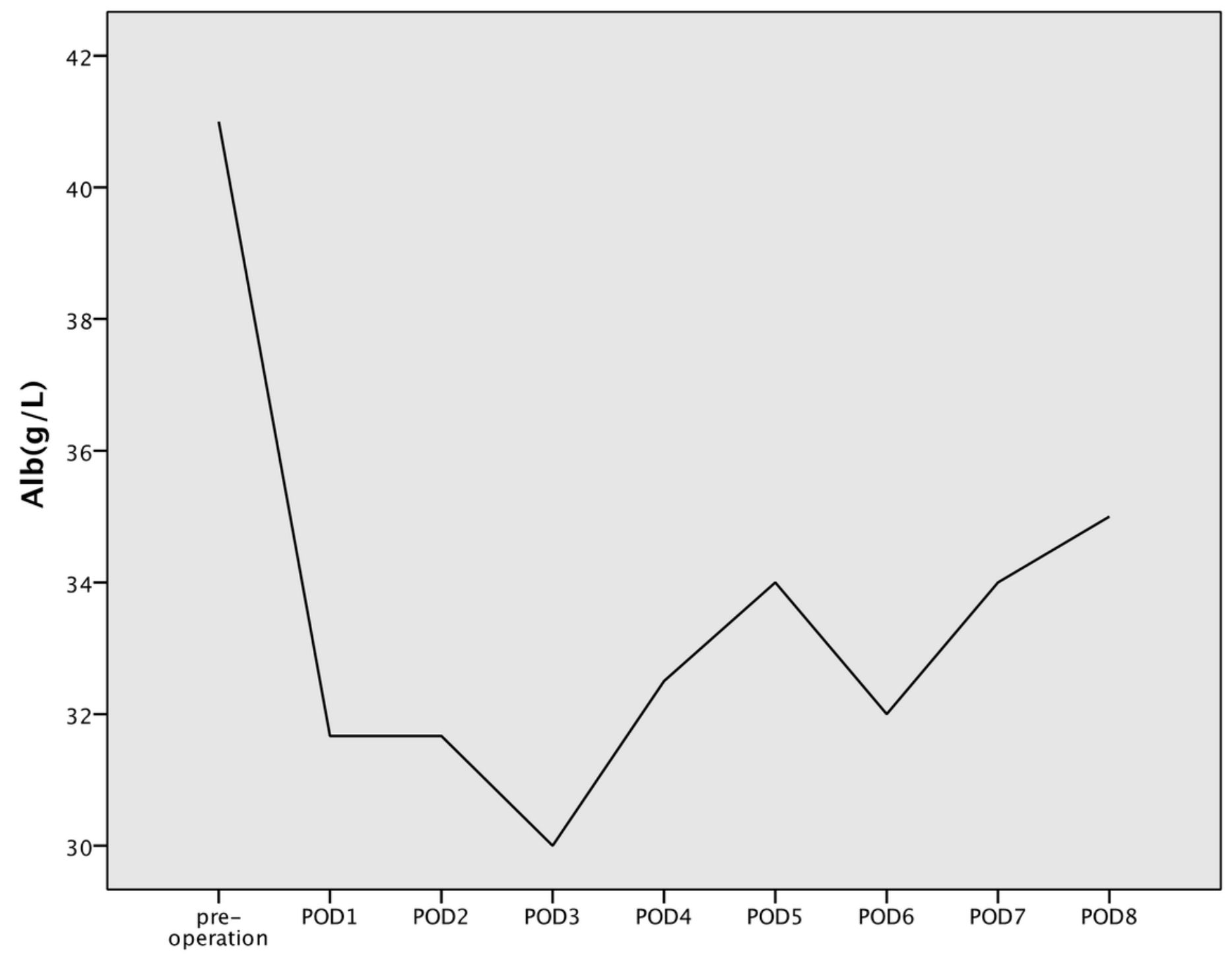

POD: Post-operative day

Figure 5

The nutritional status of 3 patient 